\title{
Pensando uma possível proposta filosófica a partir da filmografia de Denis Villeneuve
}

\author{
Alessandro Reina ${ }^{22}$ \\ Luiz Alberto Vieira Jr. ${ }^{23}$
}

\begin{abstract}
Resumo: O presente artigo tem como objetivo investigar a proposta cinematográfica do diretor canadense em ascensão Denis Villeneuve, problematizando a sua abordagem fílmica e possível convergência filosófica no trabalho com temas de profundidade reflexiva em seus projetos mais recentes como Incendies (CAN-2010), Prisoners (CAN-2013), Enemy (CAN-2013), Arrival (CAN-2016) e Blade Runner 2049 (EUA-2017), sendo capazes de incursionar o espectador à experiência do filosofar a partir da construção do filme como uma forma de pensamento.
\end{abstract}

Palavras Chaves: Denis Villeneuve, filosofia, filmes, cinema.

\section{Thinking About a possible philosophical proposal from the filmography of Denis Villeneuve}

\begin{abstract}
The present article aims to investigate the cinematographic proposal of the rising Canadian director Denis Villeneuve, problematizing his filmic approach and possible philosophical convergence in the work with themes of reflective depth in his most recent projects as Incendies (CAN-2010), Prisoners (CAN-2013), Enemy (CAN-2013), Arrival (CAN2016) and Blade Runner 2049 (USA-2017), being able to penetrate the viewer to the experience of philosophizing from the construction of the film as a way of thinking .
\end{abstract}

Key words: Denis Villeneuve, philosophy, films, cinema.

\section{Introdução}

O cinema tem apresentado propostas interessantes nos últimos anos, de um cinema comercial, mas com uma abordagem filosófica em relação à condução da narrativa fílmica. Nesse sentido, muitos destes filmes chamam a atenção dos espectadores, por abordarem questões complexas envolvendo o pensamento e a realidade que o circunda. Dentro dessa ideia, insere-se o espectador numa reflexão mais

22 Doutorando em Educação PPGE-UFPR. Mestre em Educação UFPR. Professor dos cursos de graduação e Pós-Graduação do Centro Universitário Claretiano e da Secretaria de Educação do Estado do Paraná. Pesquisador do GECINE/NESEF- Grupo de Estudos sobre Cinema e Educação do Núcleo de Estudos Sobre Ensino de Filosofia da Universidade Federal do Paraná. Coordenador do Grupo de Estudos Sobre Cinema e Educação - GECEF-CNPq Claretiano. E-mail: alessandroreina@ claretiano.edu.br

${ }^{23}$ Graduado em Filosofia e Especialista em Filosofia Contemporânea PUC-PR - Pontifícia Universidade Católica do Paraná. Professor da Secretaria de Educação do Estado do Paraná. Pesquisador do GECINE/NESEF- Grupo de Estudos sobre Cinema e Educação do Núcleo de Estudos Sobre Ensino de Filosofia da Universidade Federal do Paraná. Pesquisador CNPq do GECEF-CEUCLAR- Grupo de Estudos em Cinema e Ensino de Filosofia do Centro Universitário Claretiano. E-mail: luizjunior.vieira@gmail.com 
profunda sobre a problemática desenvolvida no filme, remetendo-se à filosofia. Muitos destes filmes constituem-se de certa potencialidade reflexiva ao conseguirem conduzir o espectador a filosofar a partir da narrativa, por meio da imagem-movimento.

Eisenstein (2002), um dos grandes cineastas russos, já alertava que a construção da narrativa pela montagem é o elemento que dá sentido ao filme. Aliás, boa parte da tradição do cinema revolucionário soviético debruçou-se sobre a importância da montagem, como Kuleshov, Pudovkin e o próprio Eisenstein. É de conhecimento geral, que não basta apenas ter um bom roteiro e saber como conduzir as filmagens de forma a desenvolver a história: é na montagem que o filme toma forma, quando suas partes se unem e ganham sentido, problematizando e engendrando uma reflexão profunda sobre os processos que dizem respeito ao ser humano e à realidade.

Porém, na atualidade, muitos outros elementos são importantes na construção de um projeto consistente do ponto de vista da crítica cinematográfica, como a fotografia, a trilha sonora e principalmente a interpretação das personagens. Dar uma profundidade filosófica ou abordar temas que envolvam uma reflexão profunda sobre questões relativas à realidade e ao ser humano tem sido difícil de se conduzir, uma vez que o cinema, desde sua origem, é visto como um negócio altamente lucrativo e os filmes mais cerebrais (filosofantes), geralmente não possuem apelo comercial.

Desta forma, construir projetos que trazem uma abordagem mais filosófica passa a ser algo complexo. No entanto, viabilizar tais projetos com potencial comercial não é algo impossível, como se observa em alguns exemplos na história recente do cinema, incluindo Matrix (EUA-1999) dos irmãos Wachovski, Inception (A Origem- EUA, 2010) de Christopher Nolan, e o mais recente e impactante Mother! (Mãe!-EUA-2017) de Darren Aronofsky. Na realidade, os filmes com potencial filosófico em sua abordagem são difíceis de se construir, pois, ou caracterizam-se como projetos independentes e circulam na periferia do cinema, ou tentam de certa forma desenvolver suas abordagens, sem perder de vista uma potencialidade comercial, o que obviamente interessa à indústria cinematográfica.

Nos últimos anos o cineasta canadense Denis Villeneuve tem chamado a atenção da crítica especializada pela forma como tem conduzido alguns projetos de maneira consistente e competente, cuja narrativa apresenta uma certa complexidade ao abordar temas eminentemente filosóficos envolvendo a psique humana. Entretanto, são filmes com potencialidade comercial que caíram no gosto do grande público. 
A ascensão de Villeneuve iniciou em 2001 com Maelstrom (Redemoinho CAN, 2001), filme bastante premiado no Canadá, e enaltece sua competência com o filme Polytechnique (Politécnica, CAN, 2009), sobre o massacre na Escola Politécnica de Montreal. Porém é a partir de seus projetos ficcionais que Villeneuve passa a conquistar um lugar seleto dentre os promissores diretores da atualidade como em Incendies (Incêndios, CAN, 2010), Prisoners (Os suspeitos, CAN, 2013), Enemy (O homem duplicado, CAN, 2013), Arrival (A Chegada, CAN, 2016) e Blade Runner 2049 (EUA-2017).

Neste artigo abordaremos os principais filmes ficcionais de Denis Villeneuve, cuja intenção é investigar a possível potencialidade filosófica do projeto recente do diretor canadense. Villeneuve tem despertado o olhar especial da crítica de cinema mundial, ao dirigir filmes cerebrais com enredo complexo como em Enemy (CAN2013) e narrativas não lineares como Arrival (CAN-2016). Destacaremos a potencialidade filosófica destes filmes, à medida que se apresentam ao público como um verdadeiro convite ao pensamento e ao filosofar.

\section{Parte 1- Incendies e Prisoners}

A história do cinema está repleta de filmes grandiosos e cerebrais. Chamamos de "filmes cerebrais" aqueles que possuem dentro de si a potencialidade de serem, de fato, filosóficos. Neste sentido, devemos inicialmente separar filmes que possuem temáticas filosóficas daqueles que são efetivamente filosóficos. Isto porque, embora possamos afirmar que na perspectiva do espectador qualquer filme possa ser filosófico- porque sempre há algo a ser problematizado-, são poucos os filmes capazes de conduzir substancialmente o espectador a filosofar a partir da imagem-movimento, caracterizando-os como um legítimo filme filosófico.

Entende-se por filosofar o processo que conduz o indivíduo a uma reflexão profunda sobre um determinado problema dentro da sua realidade, originando uma espécie de estranhamento ao pensar sobre algo que foge do senso comum cotidiano e instaurando um certo deslocamento, ao termos nosso pensamento violentado por uma força externa a nós. Deleuze (2003) ao analisar o pensamento de Proust, afirma que pensar é ser violentado pelo signo, ou seja, por uma força fora do sujeito (dehors). No cinema, alguns filmes são capazes de produzir este efeito, a saber, de agirem como uma força externa a nós, sendo capazes de produzir um deslocamento que nos tira do pensar 
cotidiano e nos conduz ao ato do filosofar.

Os projetos fílmicos de Denis Villeneuve, tem apresentado interessantes abordagens filosóficas, sendo que, a cada filme, o diretor apresenta uma espécie de evolução positiva, caminhando para a construção de filmes cada vez mais cerebrais, como afirma Cabrera (2006), como "formas de pensamento" e por si só, fílosóficos.

\begin{abstract}
A primeira vista, pode parecer assustador falar do cinema como uma forma de pensamento, assim como assustou o leitor de Heidegger ao inteirar-se que "a poesia pensa". Mas o que é essencial na filosofia é o questionamento radical e o caráter hiperabrangente de suas considerações. Isto não é incompatível, $a b$ initio, com uma apresentação imagética (por meio de imagens) de questões, e seria um preconceito pensar que existe uma incompatibilidade. (CABRERA, 2006, p. 17).
\end{abstract}

Os filmes filosóficos são aqueles que são capazes de conduzir o espectador pela narrativa fílmica a filosofar, de produzir, como afirmamos outrora, uma força que impulsione à reflexão filosófica. Não abordaremos aqui os critérios específicos que constituem o filme filosófico, uma vez que o objetivo é explorar a possível convergência filosófica nos filmes de Villeneuve. No entanto, cabe fazermos uma observação sobre o filme filosófico inicialmente: Deleuze (2007) aponta que estes filmes, são "formas de pensamento", capazes de produzir uma espécie de "choque" no espectador. Este choque caracteriza-se como uma força (dehors) que emana do filme, imprimindo agressivamente a problemática filosófica do filme na mente do espectador. Sobre isto Deleuze (2007) nos diz o seguinte:

\begin{abstract}
O homem sabe pensar na medida em que tem a possibilidade de pensar, mas este possível não garante que sejamos capazes de pensar. É essa capacidade, essa potência e não a mera possibilidade lógica, que o cinema pretende nos dar comunicando o choque. Tudo se passa como se o cinema dissesse: comigo, com a imagem-movimento, vocês não podem escapar do choque que desperta o pensador que há em vocês. (DELEUZE, 2007, p. 190).
\end{abstract}

Sobre a possibilidade do "choque" cinematográfico, podemos citar diretores clássicos como Vertov, Eisenstein, Felini, Gance, Kubrick, Kurosawa, e alguns cineastas contemporâneos como Terrence Mallick, Lars Von Trier e Michael Haneke, cujos projetos são de fato cerebrais, com a intencionalidade de provocar o choque no espectador, convidando-os a filosofar a partir das imagens.

Como a maioria dos diretores, Villeneuve teve que demonstrar sua competência na direção e condução da narrativa antes de se destacar. Neste processo, dois filmes 
foram expoentes para seu reconhecimento: Incendies (CAN-2010) e Prisoners (CAN2013). Com imbricamento bastante parecido, estes filmes detêm um tensionamento filosófico, cuja depuração e transformação para projetos mais cerebrais e filosóficos aparecem especificamente em Enemy (CAN-2013) e Arrival (CAN-2016). Para abordar este tensionamento e a incursão aventureira de Villeneuve, trabalharemos com seus dois primeiros projetos, Incendies (CAN-2010) e Prisoners (CAN-2013). Nestes, o diretor de fato demonstrou capacidade de dirigir e conduzir com competência a narrativa fílmica.

Em Incendies (Incêndios, CAN, 2010), Villeneuve encara a difícil tarefa de mergulhar numa investigação existencial envolvendo uma questão muito delicada. A película inicia com a leitura de um testamento de Nawal Marwan (Lubna Azabal), mãe dos gêmeos Jeanne (Mélissa Désormeaux-Poulin) e Simon (Maxim Gaudette). Na escritura descobrem que possuem um pai e um irmão a quem devem, segundo a mãe falecida, entregar uma carta a cada um deles. Caso recusem a tarefa, a mãe não deverá ter uma lápide em sua sepultura, devendo ser enterrada nua e de bruços para a terra, uma vez que proferiu: "não deve haver lápide para quem não cumpre suas promessas". Apesar da resistência de Simon, Jeanne resolve encarar a tarefa e ir atrás dos parentes desconhecidos, iniciando uma busca pelo passado obscuro da mãe, Nawal Marwan.

O filme traz uma emblemática questão existencial, na medida em que a imprecisão e a falta de informações, somada a angústia da busca e a ausência de paz de consciência, os dois irmãos mergulham no caos da existência. Segundo Sartre (1987), nada determina em nós uma essência prévia: nos construímos durante a vida através de nossas escolhas e de nossa liberdade, fazendo com que o futuro seja imprevisível e, de fato, angustiante.

Com efeito, se a existência precede a essência, nada poderá jamais ser explicado por referência a uma natureza humana dada e definitiva, ou seja, não existe determinismo, o homem é livre, o homem é liberdade (SARTRE, 1987, p. 9).

No início do filme, quando Jeanne é apresentada a uma de suas turmas por seu mentor, onde ela ministraria aulas de matemática pura, o mesmo diz o seguinte:

A matemática como vocês conhecem até agora tem por objetivo alcançar uma resposta rigorosa e definitiva a partir de problemas exatos e definitivos. Agora vocês entrarão em uma aventura completamente diferente. Serão discutidos os problemas insolúveis que vão sempre levar vocês a outros problemas igualmente insolúveis. (INCENDIES, 2010) 
Desde as descobertas de Newton, a modernidade considerava a matemática com a única coisa certa e evidente, como observamos através dos pressupostos da filosofia cartesiana. O projeto da modernidade encontra seu ápice com o positivismo no século XIX, quando a ciência seria a chave para a solução dos problemas humanos e universais. No entanto, com a descoberta da matemática pura, ocorre uma incerteza e o paradigma moderno e positivista é superado: a matemática não é tão certa quanto parece e alguns problemas levam a outros, complexos e insolúveis. Isso fica evidente no itinerário da busca dos irmãos Jeanne e Simon. Quanto mais Jeanne descobre variáveis desconhecidas sobre o passado da mãe, mais angustiante torna-se sua busca, colocando que a existência é também algo desconhecido e incompreensível, como Sartre (1987) aponta. Da incerteza, advém a angústia determinada. Dentro dela o ser se perde na busca por um sentido, como afirma Heidegger (2006):

Como a angústia já sempre determinada, de forma latente, o ser-no-mundo, este, enquanto ser que vem ao encontro na ocupação junto ao 'mundo', pode sentir temor. Temor é angústia imprópria, entregue a de-cadência do 'mundo' e, como tal, angústia nela mesma velada. (HEIDEGGER, 2006, p. 254).

Jeanne descobre que a mãe foi presa política, que foi torturada e estuprada na prisão, que engravidou de seu torturador e deu luz a gêmeos. Parte do mistério sobre o pai estava resolvido, porém ainda restava saber sobre o irmão desconhecido. A questão é que as variáveis desconhecidas mudariam para sempre a vida dos dois irmãos. $\mathrm{O}$ futuro agora residia na dependência da investigação do passado. O presente se faz futuro à medida que os irmãos descobrem elementos que passam a mudar a forma como encaram a vida.

Enquanto isso, Simon encontra o paradeiro do seu irmão, que está vivo e mora também no Canadá. Durante a trama, Simon acaba descobrindo que seu irmão é quem havia sido o torturador de sua mãe. O ciclo se fecha e na sequencia, Jeanne e Simon descobrem que este irmão, outrora desconhecido, é também o seu pai. A angústia é potencializada pelo horror diante da existência. Como afirma Heidegger (2006), nossa existência se dá no tempo e nela se desenrola. Nossa existência não é estática, mas acontece cronologicamente, e o que somos agora não é o mesmo que seremos daqui a dois segundos. Imersos no tempo, somos influenciados por essas mudanças que determinam o que somos por um tênue intervalo temporal.

Esta matemática incerta da existência presente em Incendies (CAN-2010), traz 
consigo a essência da problemática existencialista, em que somos "projeto de si mesmos", como afirma Sartre (1987). Neste filme, Villeneuve nos convida a filosofar a partir de um paradigma existencial, da incerteza do existir e da autenticidade do vir-aser. Ao final do filme, o ciclo de amor e ódio parece ter se rompido. Nascidos do ódio, os irmãos recebem do tabelião uma última carta da mãe, uma mensagem de amor, que evidencia que a mudança é a marca da nossa existência.

\begin{abstract}
Meus amores, aonde começa a sua história? Em seu nascimento? Então ela começa no horror. No nascimento de seu pai? Então ela começa em uma grande história de amor. Eu digo que sua história começa com uma promessa, a da ruptura do sentimento de raiva. Graças a vocês, consegui finalmente mantê-la. O fio está rompido. E eu posso finalmente ter tempo de os embalar, de cantar baixinho uma canção de ninar para os consolar. Nada é mais belo do que estarmos juntos. Eu os amo. Sua mãe, Nawal. (INCENDIES, 2010)
\end{abstract}

Após o sucesso de Incendies (Incêndios), em 2013, Villeneuve apresenta Prisoners (Os suspeitos), um suspense muito bem elaborado e extremamente bem recepcionado pela crítica especializada, com destaque para excelente atuação dos protagonistas interpretados por Hugh Jackman e Jake Gyllenhaal.

O enredo aborda o drama do pai Keller Dover (Hugh Jackman) que, após o desaparecimento súbito de sua filha, entra em desespero e cogita a possibilidade dela ter sido sequestrada, violentada e morta. Frente ao caso, está o detetive de polícia Loki (jake Gyllenhall), que toma para si a tarefa de encontrar o paradeiro da filha de Dover, envolvendo-se emocionalmente no caso.

Sem saber o paradeiro de sua filha e diante da ausência de notícias, Dover resolve agir como uma espécie de justiceiro, investigando o caso por conta própria e tomando atitudes desesperadas diante dos suspeitos do sequestro de sua filha. $\mathrm{O}$ pavor, a dúvida e o desespero desenham em Dover um personagem torturador, obstinado e, por si só, um criminoso, que passa a ser alvo da investigação de Loki. Porém, Dover experimenta aquilo que Sartre (1987) tão bem mencionou: nossas escolhas não produzem impacto somente sobre aquilo que somos. Antes disso, tudo o que está a nossa volta se altera. Nossa liberdade não é condicionada à de outros, mas somos mutuamente influenciados:

Sem dúvida, a liberdade enquanto definição do homem, não depende de outrem, mas, logo que existe um engajamento, sou forçado a querer, simultaneamente, a minha liberdade e a dos outros, não posso ter objetivo a minha liberdade a não ser que meu objetivo seja também a liberdade dos outros (SARTRE, 1987, p. 199). 
O que faz de Prisoners um filme impactante do ponto de vista filosófico é a forma como a narrativa explora o drama existencialista vivido por Dover e a potencialidade reativa humana diante de fatos inesperados, revelando o homem como alguém potencialmente livre. O roteiro, muito bem escrito por Aaron Guzikowski, envolve o espectador numa trama sentimental complexa, onde o "mocinho" torna-se o "vilão", que, invertendo os papéis, exigemv do espectador um juízo moral sobre o problema vivido pelas personagens. O roteiro cria um ambiente claustrofóbico, fazendo do espectador um prisioneiro dos eventos vivenciados no filme, elemento que nos chama a atenção pelo título original Prisoners - "prisioneiros".

O existencialismo afirma que o covarde se faz covarde que o herói se faz herói; existe sempre, para o covarde, uma possibilidade de não mais ser covarde, e, para o herói, de deixar de o ser (Sartre, 1987, p. 14).

No entanto, as personagens também se tornam prisioneiras quando se percebe que os eventos mergulham numa espécie de trama emocional, onde os limites do que é certo e errado passam a ser questionados. Dessa forma, estabelece-se novas fronteiras e possibilidades a partir do julgamento das personagens envolvidas na história, gerando um dilema ético. O interessante é como as escolhas realizadas por Dover, que ilustram a potencialidade dele como um ser livre, configuram uma verdadeira prisão, uma vez que contrariam os seus princípios mais elevados da moralidade cristã. Isso pode ser visto quando Dover, pouco antes de torturar um suspeito do sequestro de sua filha (Paul Dano), reza pedindo perdão a Deus pelo que vai fazer. Segundo Sartre (1987), a existência ou não de Deus não tem quaisquer consequencia sobre nossa existência, uma vez que nossa liberdade resulta de nossas escolhas. Essa ideia transmite uma contradição quando relacionada à atitude de Dover e sua crença. Somos responsáveis pelo que fazemos e pelo que escolhemos.

\footnotetext{
O existencialismo não é tanto um ateísmo no sentido em que se esforçaria por demonstrar que Deus não existe. Ele declara, mais exatamente: mesmo que Deus existisse, nada mudaria, eis nosso ponto de vista. Não que acreditamos que Deus exista, mas pensamos que o problema não é de sua existência, é preciso que o homem se reencontre e se convença de que nada pode salvá-lo dele próprio, nem mesmo uma prova válida da existência de Deus (SARTRE, 1987, p. 22).
}

Dover (Hugh Jackman) e Loki (Jake Gyllemhall) se envolvem no problema do sequestro de formas distintas: enquanto Loki tenta manter a linha, Dover, o pai, toma 
atitudes desesperadas, renunciando inclusive a princípios de suas crenças. Isso fica evidente na cena em que Dover tortura um jovem suspeito do sequestro (Paul Dano), que não passa de uma vítima. Observa-se, neste contexto, uma inversão de valores, pois enquanto o detetive Loki (uma referência ao deus pagão da mitologia nórdica) representa o centrismo moral do filme, Dover o cristão devoto, rompe paradigmas ao assumir o lado mais obscuro de sua própria natureza. Não é o sentimentalismo de Dover que se coloca como uma solução para o problema, mas sim a paciência e racionalidade de Loki. O filme também coloca em oposição as duas variantes da natureza humana: razão e emoção. Entretanto, percebe-se na narrativa, que a ausência de controle de Dover levam-no para um caminho perigoso, enquanto Loki, ainda que envolvido emocionalmente pela história, consegue distanciar-se do problema, analisando-o e pensando-o de forma mais racional. Uma emoção é uma transformação do mundo que nos impele a agir.

\footnotetext{
Quando os caminhos traçados se tornam demasiado difíceis ou quando não vemos caminho algum, verificamos que não podemos continuar num mundo tão urgente e tão difícil. Todas as vias são barradas e, apesar disso, é preciso agir. (SARTRE, 1994, p. 55).
}

Neste projeto Villeneuve conseguiu demonstrar, assim como em Incendies (Incêndios) em 2010, o seu talento na condução de narrativas complexas, que trabalham não somente no sentido de explorar as emoções dos personagens, mas também de problematizar questões relativas à sociabilidade e aos limites da natureza humana. $\mathrm{O}$ nível de complexidade de trabalho com a narrativa, atinge o status de filosófico nos seus dois projetos seguintes: Enemy (O homem duplicado), de 2013, e Arrival (A chegada), de 2016, que analisaremos a seguir.

\section{Parte 2 - Enemy e Arrival}

Se é possível distinguir um filme que possui conotação filosófica a partir de seu tema, daqueles que são apenas formas de pensamento, Villeneuve deu esse salto ainda em 2013, mesmo ano em que lançou Prisioners, ao ter adaptado a obra de José Saramago "O homem duplicado". Dessa vez temos um filme no qual a reflexão depende de uma participação mais ativa do espectador, cabendo a este a interpretação acerca do fluxo narrativo, como já está proposto na epígrafe do filme (e também do livro): “o caos é uma ordem a ser decifrada". Essa participação do sujeito na construção da experiência 
fílmica é uma condição importante para aquilo que Julio Cabrera (2006) chamou de logopatia:

A racionalidade logopática do cinema muda a estrutura habitualmente aceita do saber, enquanto definido apenas lógica ou intelectualmente. Saber algo, do ponto de vista logopático, não consiste somente em ter "informações”, mas também em estar aberto a certo tipo de experiência e em aceitar deixar-se afetar por uma coisa de dentro dela mesma, em uma experiência vivida (CABRERA, 2006, p.21).

A princípio, Enemy parece ser um filme sobre um professor universitário (Adam) vivido por Jake Gyllenhaall, que se demonstra constantemente cansado e apático. Um dia, o professor Adam decide assistir a um filme indicado por um colega e se espanta ao perceber que o coadjuvante é idêntico a ele. Em um filme qualquer, essa premissa seria desenvolvida através do suspense em descobrir a natureza do duplo de Adam, se é um sósia, um clone, um irmão gêmeo que ele desconhece ou algo do tipo. Porém, o roteiro de Javier Gullón rapidamente nos faz conhecer esse duplo, um aspirante a ator chamado Anthony que está em constante atrito com a esposa, grávida de seis meses e desconfiada da fidelidade do marido. $\mathrm{O}$ que mais importa aqui para o roteiro não é explicar o mistério entre os dois homens idênticos, mas sim criar uma teia de simbolismos para forçar o espectador a cumprir a proposta da epígrafe do filme: organizar o caos.

Entre esses simbolismos o mais importante é o da "aranha", que aparece simbolicamente em diversos momentos do longa-metragem. Evidentemente ela está relacionada com o universo feminino das personagens centrais. Em uma primeira análise somos levados a crer que a aranha está relacionada principalmente com a infidelidade de Anthony, o demônio interior que o atormenta. Mas, se ela é o nêmesis de Anthony, porque Adam também a vê no final do filme? Aqui é possível perceber que a obra consegue criar um espectro visual que representa a própria estrutura do roteiro: ao longo do filme vemos diversos padrões que remetem a teias, desde cabos de energia na cidade até uma vidraça trincada de um carro. No entanto, é instigante perceber que a aparente confusão causada pelo filme se deve a estrutura do roteiro. Ao mentalizar cada cena separadamente, poderíamos imaginar que cada uma delas é um nó em uma extremidade de uma teia. Dessa forma os padrões nos levam a um nó central, o que seria a ideia chave para organizar o caos da narrativa: Adam e Anthony são a mesma pessoa. 
Segundo Cabrera (2006) os filmes filosóficos são capazes de produzir conceitosimagem, ou seja, reflexões não necessariamente apresentadas por meio da linguagem ordinária, mas por uma linguagem imagética que se constrói com a temporalidade intrínseca ao filme. Sobre o processo de significação o autor esclarece a questão do subjetivismo interpretativo.

\begin{abstract}
Os conceitos-imagem podem ser desenvolvidos no nível literal do que está sendo mostrado nas imagens (por exemplo, a intolerância no filme homônimo de Griffith, em que são apresentadas, literalmente, em cenas de intolerância), mas também podem ser desenvolvidos em um nível ultra-abstrato (CABRERA, 2006, p.25).
\end{abstract}

Essa é uma característica de Enemy "O homem duplicado" que está presente em muitos dos filmes considerados "cerebrais": não há uma única interpretação válida. A cena em que vemos Adam e Anthony (Jake Gyllenhaall) se encontrando pela primeira vez pode ser interpretada tanto literalmente quanto figurativamente, ou seja, aquele encontro pode simbolizar o choque entre o passado e o presente do personagem, ou entre suas personalidades dissuadas. Enemy, portanto, marca definitivamente uma guinada na filmografia recente de Villeneuve promovendo a incursão dos seus filmes a um universo mais filosofante.

Em 2016, Villeneuve alcançou o seu auge até então ${ }^{24}$. Junto com o roteirista Eric Heisserer adaptou o conto de Ted Chiag "The Story of Your Life” no longa de ficçãocientífica Arrival (A Chegada - EUA-2016) que conta com a atuação dos atores Amy Adams, Jeremy Renner e Forest Whitaker. Neste longa, Villeneuve volta a investir em uma narrativa que força o espectador a confrontar o seu pensamento com as questões colocadas pelo filme. No entanto, é interessante como o diretor aborda aqui uma reflexão instigada pelos elementos da trama em si e pela própria linguagem do filme, o qual evoca o problema por ele levantado, seja pela estrutura do roteiro em si ou pela natureza da montagem.

O poder reprodutivo e produtivo da imagem em movimento marca o caráter emergente do cinema e também o distingue, algo só possível graças a fotografia em movimento. O que marca a diferença são a temporalidade e a espacialidade particulares do cinema, sua capacidade quase infinita de montagem e remontagem, de inversão e de recolocação de elementos, a estrutura de seus cortes etc. (CABRERA, 2006, p. 29).

\footnotetext{
${ }^{24}$ Em 2015 Villeneuve viria a dirigir o thriller de ação "Sicário" no qual a protagonista vivida por Emily Blunt é uma agente do FBI que fica encarregada pela operação de captura de um chefe de tráfico de drogas em um cartel mexicano. Não vemos em Sicário um apelo de fato filosófico, entretanto é um filme competente em retratar situações de tensão psicológica extremas. (N.do A)
} 
O roteiro de Heisserer acompanha duas tramas em paralelo. Logo no início do filme vemos uma montagem de cenas que acompanham a personagem Louise (Adams) e seu relacionamento com a filha, desde o nascimento até a sua morte prematura, ainda na adolescência. Depois somos reapresentados a Louise em seu ambiente de trabalho, uma universidade onde leciona linguística, e assistimos à chegada de uma dúzia de naves extraterrestres na Terra, as quais se posicionam ao redor do planeta inteiro. Daí em diante Louise é contatada pelo governo para tentar decifrar a linguagem utilizada pelos visitantes alienígenas. Conforme Louise consegue estabelecer uma comunicação com os seres extraterrestres, através da escrita, ela passa também a ser constantemente atormentada por recordações de sua filha. A pressão dos seus superiores para que ela consiga descobrir o objetivo dos visitantes e as lembranças traumáticas da filha colocam-na em um crescente estresse emocional que passa a ser conflito da narrativa.

A ambição do filme de Villleneuve é rapidamente percebida pela sua estética, que em diversos momentos chega a lembrar o clássico de Kubrick "2001: uma odisséia no espaço" (EUA-1968), seja pelos planos que centralizam a protagonista dentro enquadramento, ou pela direção de arte, que opta por um minimalismo na representação das naves dos extraterrestres, divergindo da maior parte das produções atuais do gênero. Aliás, as opções estéticas do filme são fundamentais para manter a sensação "motor" do conflito da narrativa: o mistério. Nesse sentido, a música composta por Jóhan Jóhannnsson se mostra eficiente, criando uma atmosfera que ajuda a compor as sensações de fascínio e medo das personagens. Esse efeito foi conseguido através da sobreposição de diversas faixas sonoras em velocidades diferentes, que, aliado a vocalizações humanas bastante incomuns, acabou gerando um efeito perturbador no ouvinte.

Não apenas a trilha sonora, mas também o desenho de som de Arrival (A Chegada) são precisos, tanto ao criar os ruídos e sons produzidos pelos alienígenas, quanto ao ressaltar detalhes da atuação de Amy Adams, naquilo que é um fator fundamental em qualquer filme: o princípio de identificação.

No cinema, o que fundamenta a possibilidade da identificação secundária, diegética, a identificação com o representado, por exemplo, com o personagem no caso de um filme de ficção - é, em primeiro lugar, a capacidade do espectador de identificar-se com o sujeito da visão, com o olho da câmera que viu antes dele, capacidade de identificação sem a qual o filme nada seria senão uma sucessão de sombras, de formas e de cores, literalmente "não identificáveis" em 
uma tela. (AUMONT, 2014, p.259)

Ciente de que o resultado que se almeja produzir no espectador depende da sua identificação com o drama da personagem, Villeneuve e seu diretor de fotografia Bradford Young, posicionam constantemente o eixo da câmera na altura dos olhos da personagem, ou mesmo utilizam o recurso de câmera subjetiva para que, em determinados momentos do filme, possamos enxergar as coisas da mesma maneira que a protagonista. Esses recursos, tanto sonoros quanto visuais, ficam bastante evidentes na cena na qual Louise tem seu primeiro contato com a "concha" e os seres que vieram nela, onde a imagem observada pelo espectador corresponde àquela vista pela personagem da cena, e o som é representado pela sua respiração ofegante de dentro da roupa de proteção que a personagem está usando.

Nessa cena outro recurso é utilizado pela fotografia para ilustrar o conceito de múltiplas dimensões espaciais na "concha". Enquanto vemos os protagonistas entrarem dentro dela pela primeira vez, a cada corte de plano o próximo é montado espacialmente invertido em relação ao anterior, o que gera a sensação de que naquele lugar não existe “em cima" ou "embaixo". O efeito é reforçado pela utilização do famoso "efeito vertigo" criado por Hitchcock no seu filme homônimo. Assim que as personagens pisam na concha, a profundidade de campo é deformada com a câmera, fazendo um movimento de zoom contrário a movimentação da própria câmera.

Do ponto de vista conceitual, Arrival (A Chegada) levanta um curioso problema entre linguagem e pensamento. A personagem de Louise rapidamente estabelece um código de comunicação com os seres visitantes através de símbolos, que eles passam a projetar em uma tela que os separa dos terráqueos. Ao perceber que a criação desses símbolos parece conter diversos aspectos de pensamento simultâneos, Louise entende que eles não configuram palavras específicas ou ideais simples, mas mensagem inteiras dentro de cada símbolo. Além disso, os símbolos são circulares e surgem de dentro dos tentáculos dos alienígenas, do exterior para a borda do círculo, o que dificulta determinar o início e o fim da frase. O filme chega a mencionar a chamada hipótese de Sapir-Whorf para descrever o motivo dos visitantes se comunicarem dessa forma. Essa hipótese estabelece que a linguagem determina as formas de pensamento do indivíduo ou cultura:

O nome de Benjamin Lee Whorf está associado a uma teoria da relatividade linguística que é conhecida por vários títulos - "a hipótese Sapir-Whorf”, "a 
hipótese Whorf”, “a hipótese Whorf-Lee”. A relatividade cultural simples afirma que todo ser humano nasce em um meio cultural que determina quais elementos do mundo serão importantes para o indivíduo por meio de seus métodos de educação infantil e de reforço cultural. O acréscimo particular de Whorf a esse princípio da relatividade cultural foi sua afirmação da primazia da língua nesse processo de seleção (MACHADO, 2015, p. 44)

E novamente Villeneuve demonstra a sua perícia com a linguagem cinematográfica, ao utilizar a própria estrutura do roteiro e da montagem, para ilustrar a conclusão à qual Louise chega: os visitantes possuem uma percepção do tempo circular e por isso sua linguagem assume essa forma. O filme por sua vez, aposta na convenção do efeito Kuleshov ${ }^{25}$ para surpreender o espectador: logo após a cena de introdução na qual acompanhamos o nascimento e morte da filha de Louise, nós a encontramos indo para a faculdade onde ministra suas aulas. Devido a sequência anterior, somos levados a projetar no semblante de Louise a recuperação do luto pela sua filha. Porém, por volta do terceiro ato, descobrimos que aquela cena não é uma lembrança, mas algo que ainda vai acontecer. Somente depois da chegada das conchas é que Louise viria a ter sua filha. Nesta inversão de cena, a montagem atinge dois efeitos: confere a própria narrativa o caráter circular do pensamento dos visitantes e aumenta no espectador a conexão emocional com Louise, potencializando o seu conflito numa clara demonstração de como a logopatia opera:

Os conceitos-imagem do cinema, por meio desta experiência instauradora e plena, procuram produzir em alguém (um alguém sempre muito indefinido) um impacto emocional que, ao mesmo tempo, diga algo a respeito do mundo, do ser humano, da natureza etc. E que tenha um valor cognitivo, persuasivo e argumentativo através de seu componente emocional (CABRERA, 2006, p.22).

Logo após ter feito esta sua primeira incursão na ficção científica, Villeneuve se viu diante de um projeto ainda mais desafiador: rodar uma sequência para o clássico Blade Runner - Caçador de Andróides (EUA-1982). Este foi dirigido por Ridley Scott, que aparece como produtor executivo na sequência de Villeneuve: Blade Runner 2049 (EUA-217). Mesmo sendo o projeto de maior custo e responsabilidade que Villeneuve já enfrentara, o diretor aceitou a proposta, dirigindo um filme que consegue homenagear o clima noir e futurista. Além de trazer novos personagens, Villeneuve reinventa aquela distopia que intercala a problemática emblemática que envolve ética e tecnologia, algo

\footnotetext{
${ }^{25}$ Técnica de edição criada pelo cineasta russo Lev Kuleshov (1899-1970), onde o corte e a montagem determinam o significado de uma sequência de cenas filmadas, que passa a depender da interpretação subjetiva do espectador, já que as cenas ou imagens isoladas não possuem sentido algum.
} 
bastante comum à geração "Black Mirror" 26 .

A experiência fílmica aqui é muito mais densa do que em seus trabalhos anteriores e o diretor não demonstra pressa em realizar cortes, nos permitindo acompanhar cuidadosamente a investigação da personagem "K" (Ryan Gosling). Esta personagem aparece como o novo caçador de andróides, uma referência à personagem Rick Deckard (Harisson Ford), representado como caçador de andróides do primeiro filme, de 1982. Blade Runner (EUA-1982), trazia às telas um problema intrigante: num futuro distópico, a empresa Tyrell Corporation tentava caçar andróides que haviam desenvolvido "consciência", os chamados "replicantes", originados devido a um erro de programação. Para tanto, a Tyrell utilizava-se de "blade runners", caçadores implacáveis que tinham como objetivo "aposentar" os replicantes. O grande desafio para os caçadores era conseguir identificar os replicantes e diferenciá-los dos humanos, já que aqueles detinham consciência e assemelhavam-se aos humanos, A questão, comum hoje à Filosofia da Mente e tão amplamente discutida a partir do famoso Teste de Turing, ganha contornos angustiantes quando surge o dilema acerca do próprio caçador de replicantes, Rick Deckard (Harisson Ford): humano ou andróide?

Já a sequência dirigida por Villeneuve - Blade Runner 2049 (EUA-2017) inova, pois foge da receita original do primeiro filme, (algo que o roteiro não nos respondeu em Blade Runner - O caçador de Andróides). Se no primeiro longa tínhamos dúvidas quanto a humanidade de Deckard, no segundo filme esta dúvida é resolvida sobre a identidade do personagem principal "K" (Ryan Gosling). "K" é de fato um androide, porém, de forma magistral, o roteiro de Hampton Fancher e Michael Green não foca objetivamente neste problema, mas sobre o que faz de nós verdadeiramente humanos. Em uma das cenas do filme, "K", enquanto procede em sua investigação sobre os replicantes remanescentes, hesita sobre uma de suas memórias, não sabendo determinar se estas seriam realmente dele ou se teriam sido implantadas, enquanto replicante. Eis que conclui que isso não importava, pois elas haviam sido "reais" para ele, o que nos eleva a um outro patamar sobre a reflexão daquilo que faz de nós humanos: não a legitimidade dos fatos vividos, mas a certeza de que os vivenciamos internamente ou subjetivamente, assumindo certo valor para nós. Essa ideia resolveria também o próprio

\footnotetext{
${ }^{26}$ Black Mirror é uma série de ficção científica britânica criada por Charlie Brooker para a TV, exibida atualmente pela empresa NETFLIX. A série brinca com um futuro distópico, onde evidencia a dificuldade do ser humano de relacionar-se com a tecnologia onde os limites éticos são ultrapassados, provocando um mal-estar na civilização.
} 
argumento proposto por Searle, do quarto chinês, uma vez que, se uma máquina conseguisse decifrar o sentido de uma mensagem (sentido que o ser humano a toma), poderia de fato pensar como humano.

Embora o argumento do quarto chinês de Searle, demonstre uma impossibilidade da máquina pensar como ser humano, pois age através de uma programação incapaz de pensar sobre o sentido da informação, fica claro que a imaginação dos roteiristas de Blade Runner fornece uma resposta criativa a esta questão filosófica. Interessante que, a questão filosófica central proposta por Blade Runner 2049 e sua aparente resposta à questão, evoca um problema clássico da história da filosofia e sua solução igualmente emblemática: o cogito cartesiano.

\begin{abstract}
E enfim, considerando que todos os mesmos pensamentos que temos quando despertos nos que podem também ocorrer quando dormimos, sem que haja nenhum, nesse caso, que seja verdadeiro, resolvi fazer de conta que todas as coisas que até então haviam entrado no meu espírito não eram mais verdadeiras que as ilusões de meus sonhos. Mas, logo em seguida, adverti que, enquanto eu queria assim pensar, que tudo era falso, cumpria necessariamente que eu, que pensava, fosse alguma coisa. E, notando que esta verdade: eu penso, logo existo, era tão firme e tão certa que todas as mais extravagantes suposições dos céticos não seriam capazes de a abalar, julguei que podia aceitá-la, sem escrúpulo, como o primeiro princípio da filosofia que procurava (DESCARTES, 1996, p.92).
\end{abstract}

A partir do cogito cartesiano percebemos que o "real" se deu pela vivência subjetiva, afinal, segundo Descartes, não importa a veracidade do "conteúdo sobre o que se pensa", mas sim de que há uma verdade implícita e incontestável, a saber, de que se “está pensando algo e se tem consciência disso", não importa o que seja pensado. É esta a conclusão da personagem "K", que, independente de ser ou não um andróide, sentiase humano, pois sua consciência e subjetividade lhe proporcionaram a sensação do real vivido, mesmo tendo sido memórias que lhe foram implantadas pela Tyrell Corporation. Interessante a forma como os roteiristas criaram este desfecho, pois se Blade Runner (EUA-1982) levantava esta problemática sobre o que poderia diferenciar um robô de um humano, a resposta foi servida "de bandeja" na sequência Blade Runner 2049 (EUA-2017).

O roteiro do filme consegue ampliar ainda mais essa discussão, já presente no filme anterior, e torná-la ainda mais interessante, já que em determinado momento, um personagem ciente de que é um andróide e de que suas memórias são fabricadas e implantadas artificialmente, começa a se questionar se isso diminui o fato de estar existindo. A força narrativa de Blade Runner 2049 está em transportar a constatação do 
cogito cartesiano para condições de vida mais miseráveis do que a humana o que nos leva a um interessante exercício de empatia, movido por lógos e páthos, fazendo de Villeneuve um habilidoso diretor ao trabalhar e propor reflexões filosóficas emblemáticas e de difícil compreensão ao espectador.

\section{Considerações finais}

Embora sua carreira ainda esteja em ascensão, Dennis Villeneuve é um cineasta que tem contribuído através de suas obras para o debate acerca de um cinema possivelmente filosófico ou filosofante, de forma até mesmo ambivalente, ao trabalhar não somente dentro da perspectiva do cinema autoral, onde o diretor é também roteirista, mas na adaptação de algumas narrativas como é o caso de Blade Runner 2049, originalmente concebido por Ridley Scott. Em seus filmes é possível encontrar pelo menos dois modos através dos quais a filosofia pode se conectar ao cinema.

Conforme Reina (2016), uma dessas vias é a de ilustração, na qual um conceito ou um problema filosófico por ser explicitado pela trama, como as questões existenciais presentes em Os Suspeitos (Prisoners-2013), Incêndios (Incendies-2010) e Blade Runner 2049 (EUA-2017). A outra via é a da produção de pensamento (problematização) a partir do "enfrentamento" do filme, como a tentativa subjetiva em organizar a narrativa, no caso de Enemy (O Homem Duplicado-2013), e a diligência em interpretar os símbolos que remetem ao conflito emocional do personagem.

Ainda, faz-se possível um meio termo entre essas vias, como em Arrival (A Chegada-2016), filme no qual a reflexão filosófica parte não apenas da trama em si como também é explicitada pela montagem semântica do filme. O próximo trabalho que veremos do jovem cineasta canadense será a adaptação da obra Duna de Frank Hebert. Este é um projeto ainda mais sublime, já que será a segunda tentativa de conceber um filme que acabou se tornando lendário devido a sua inconclusão por Alejandro Jodorowsky, que, aliás, é outro cineasta merecedor de uma reflexão mais detalhada envolvendo sua filmografia.

De fato, há muita competência e arrojo nos projetos assumidos por Villeneuve, contradizendo um elemento mítico que reside na ideia de que bons filmes são totalmente autorais, pois Villeneuve, em suas adaptações, consegue executar um projeto com exímio talento. Se por um lado a competência de Villeneuve é uma realidade, teremos de esperar para ver se ela não é de fato momentânea e se a proposta de abordagem filosófica de cinema de Villeneuve irá ter um efeito duradouro em sua 
carreira ou sucumbirá com o tempo diante de projetos mais audaciosos e/ou comerciais.

Submetido em janeiro de 2018.

Referências

Aprovado em abril de 2018.

AUMONT, Jacques. A estética do filme. Campinas, Papirus, 2012.

CABRERA, J. O cinema pensa: uma introdução à filosofia através dos filmes. Rio de Janeiro: Rocco, 2006.

MACHADO, Isadora. A reinvenção da "hipótese Sapir-Whorf" in Línguas e Instrumentos Linguítiscos - No 35 - jan-jun 2015.

DELEUZE, G. Cinema II: a imagem-tempo. São Paulo: Brasiliense, 2007.

Forense, 2003.

Proust e os Signos. Trad. Antônio Carlos Piquet e Roberto Machado.

DESCARTES. O discurso do método. São Paulo: Nova Cultural, 1996.

EISENSTEIN, S. O sentido do filme. Rio de Janeiro: Zahar, 2002.

HEIDEGGER, Martin. Ser e Tempo. Petrópolis: Vozes, 2006.

REINA, A. Cinema e Filosofia. Como ensinar e aprender filosofia com os filmes. Curitiba: Juruá, 2016.

SARTRE. Jean Paul. O existencialismo é um humanismo. São Paulo: Nova Cultural, 1987.

Esboço de uma teoria das emoções. Rio de Janeiro, Zahar, 1994.

\section{Filmografia}

ARRIVAL (A Chegada). Direção de Denis Villeneuve. EUA: Paramount Pictures, 2016.

BLADE RUNNER 2049. Direção de Denis Villeneuve. EUA: Imagem Filmes, 2017.

ENEMY (Homem Duplicado). Direção de Denis Villeneuve, Canadá/Espanha: Imagem Filmes, 2013.

INCENDIES (Incêndios). Direção de Denis Villeneuve. Canadá/França: Happiness Distribution, 2010. 
INCEPTION (A Origem). Direção de Christopher Nolan. EUA: Warner Bros Pictures, 2010.

MATRIX. Direção Irmãs Wachowski. EUA: Warner Bros Pictures, 1999.

MAELSTROM (Redemoinho). Direção de Denis Villeneuve. Canadá: Max Film Productions, 2000.

POLYTECHNIQUE (Politécnica). Direção de Denis Villeneuve. Canadá: Remstar Productions Inc., 2009.

PRISONERS (Os Suspeitos). Direção de Denis Villeneuve. EUA: Warner Bros Pictures, 2013. 